\title{
Is "DevoManc" devolution, delegation, or dismantling of the NHS?
}

\section{Fiona Godlee editor in chief}

The BMJ; fgodlee@bmj.com

It's been said that only two things will survive a nuclear holocaust: cockroaches and regional health authorities. Does the Greater Manchester experiment in devolution-otherwise known as DevoManc - show the extraordinary regenerative powers of NHS regions, as they once more refuse to lie down and die?

Reduced in number from 14 to eight in 1994, England's regional health authorities were transmogrified into 10 strategic health authorities in 2006 , only to be vapourised altogether by the Lansley reforms in 2013.

Now, in what Richard Vize (doi:10.1136/bmj.i1611) calls "one of the most radical NHS experiments since local authorities were stripped of health responsibilities in 1948," they could be making a comeback. From April 1, Greater Manchester will take charge of its entire $£ 6 \mathrm{bn}$ health and social care budget under a newly formed strategic partnership board.

Several of those interviewed by Vize question whether this is true devolution or mere delegation. The government's mandate still applies, and national strategies and targets remain. Some worry that it is actually a dismantling of the NHS. "The debate about how we should fund the NHS will turn into a debate about how badly local authorities are managing the NHS," says one commentator.

Others see promising remedies for the current system's fragmented and vertically siloed structures. Under the new plan,
Manchester's foundation trusts will lose their autonomy, forcing a more holistic response to the population's needs. Not only will this move resources into the community, it will, if successful, reach beyond the traditional boundaries of health and social care into the wider economy. Says another commentator, "We can have an impact not just on care but on crime, worklessness, the benefits system."

But herein may lie one of many obstacles to success, say Kieran Walshe and colleagues (doi:10.1136/bmj.i1495). Will care providers be willing to see their resources transferred to criminal justice, housing, and employment in the interests of the greater good?

The scale of the financial and organisational challenge is enormous, and the stakes are high. If Manchester succeeds, others may follow. NHS England may simply be too big to work as a single entity. Scotland, Wales, and Northern Ireland already provide natural experiments in autonomous health systems serving populations of 5 million or less. With 2.7 million inhabitants, Greater Manchester could prove both small enough to manage and big enough to matter. If so I will be the first to say, come back regional health authorities, all is forgiven.

Greater Manchester could prove both small enough to manage and big enough to matter. If so I will be the first to say, come back regional health authorities, all is forgiven. 